\title{
Article
}

\section{In Vitro Cytotoxic Effects of Secondary Metabolites Present in Sarcopoterium Spinosum L.}

\author{
Jozef Hudec ${ }^{1}$, Jan Mojzis ${ }^{2}$, Marta Habanova ${ }^{3, *(D)}$, Jorge A. Saraiva ${ }^{4}\left(\mathbb{D}\right.$, Pavel Hradil $^{5}$, Tibor Liptaj ${ }^{6}$, \\ Lubomir Kobida ${ }^{7}$ (D), Miroslav Haban ${ }^{7,8}$, Maria Holovicova ${ }^{9}$ and Dominika Zvercova ${ }^{7}$
}

Citation: Hudec, J.; Mojzis, J.; Habanova, M.; Saraiva, J.A.; Hradil, P.; Liptaj, T.; Kobida, L.; Haban, M.; Holovicova, M.; Zvercova, D. In Vitro Cytotoxic Effects of Secondary

Metabolites Present in Sarcopoterium Spinosum L. Appl. Sci. 2021, 11, 5300. https://doi.org/10.3390/app11115300

\section{Academic Editors:}

Magdalena Czlapka-Matyasik,

Antonio Valero, Jadwiga Hamułka and Magdalena Zielińska-Dawidziak

Received: 17 April 2021

Accepted: 4 June 2021

Published: 7 June 2021

Publisher's Note: MDPI stays neutral with regard to jurisdictional claims in published maps and institutional affiliations.

Copyright: (C) 2021 by the authors. Licensee MDPI, Basel, Switzerland. This article is an open access article distributed under the terms and conditions of the Creative Commons Attribution (CC BY) license (https:// creativecommons.org/licenses/by/ $4.0 /)$.
1 Department of Agrochemistry and Plant Nutrition, Faculty of Agrobiology and Food Resources, Slovak University of Agriculture in Nitra, Tr. A. Hlinku 2, 94976 Nitra, Slovakia; jahc.13@gmail.com

2 Department of Pharmacology, Faculty of Medicine, Pavol Jozef Šafárik University in Košice, Trieda SNP 1, 04011 Košice, Slovakia; jan.mojzis@upjs.sk

3 Department of Human Nutrition, Faculty of Agrobiology and Food Resources, Slovak University of Agriculture in Nitra, Tr. A. Hlinku 2, 94976 Nitra, Slovakia

4 QOPNA \& LAQV-REQUIMTE, Department of Chemistry, University of Aveiro, 3810-193 Aveiro, Portugal; jorgesaraiva@ua.pt

5 Department of Organic Chemistry, Faculty of Science, Palacky University Olomouc, Tr. 17. Listopadu, 1192/12, 77146 Olomouc, Czech Republic; pavel.hradil@upol.cz

6 Central Laboratories, Faculty of Chemical and Food Technology, Slovak University of Technology in Bratislava, Radlinského 9, 81237 Bratislava, Slovakia; tibor.liptaj@stuba.sk

7 Department of Sustainable Agriculture and Herbology, Faculty of Agrobiology and Food Resources, Slovak University of Agriculture in Nitra, Tr. A. Hlinku 2, 94976 Nitra, Slovakia; lubomir.kobida@uniag.sk (L.K.); miroslav.haban@gmail.com (M.H.); xzvercova@uniag.sk (D.Z.)

8 Department of Pharmacognosy and Botany, Faculty of Pharmacy, Comenius University in Bratislava, 83232 Bratislava, Slovakia

9 AgroBioTech Research Centre, Slovak University of Agriculture in Nitra, Tr. A. Hlinku 2, 94976 Nitra, Slovakia; mariaholovicova23@gmail.com

* Correspondence: marta.habanova@uniag.sk; Tel.: +421-376414467

\begin{abstract}
Sarcopoterium spinosum (L.) is a medicinal plant traditionally used for the treatment of various diseases including cancer in the Near- and Middle East. The fractions and constituents of the ethanol extract of S. spinosum were screened for in vitro cytotoxic activities on Jurkat (acute T-lymphoblastic leukemia), HeLa (cervical adenocarcinoma), MCF-7 (mammary gland adenocarcinoma), Caco-2 (human colorectal adenocarcinoma), and MDA-MB-231 (mammary gland adenocarcinoma) cell lines using the MTT (3-(dimethylthiazol-2-yl)-2,5-diphenyltetrazolium bromide) assay. The ethanol extract was subsequently re-extracted with ethyl acetate and in its sub-fraction obtained by column chromatography three compounds (stachydrine, benzalkonium chloride and rutine) were the first time identified by nuclear magnetic resonance (NMR) analyses. The most active subfraction showed cytotoxic activity against HeLa, MCF-7, and Caco-2 cell lines. The three compounds mentioned, as standards of high-performance liquid chromatography (HPLC) quality, were studied individually and in combination. Cytotoxic activity observed might be due to the presence of benzalkonium chloride and rutin. Benzalkonium chloride showed the strongest growth suppression effect against HeLa cells ( $\mathrm{IC}_{50} 8.10^{-7} \mathrm{M}$ ) and MCF-7 cells ( $\mathrm{IC}_{50} 5.10^{-6} \mathrm{M}$ ). The mixture of stachydrine and benzalkonium chloride allowed a synergistic cytotoxic effect against all tested cancer and normal cells to be obtained. Anti-cancer activity of the plant extract of S. spinosum remains under-investigated, so this research describes how the three major compounds identified in the ethyl acetate extract can exert a significant dose dependent in vitro cytotoxicity.
\end{abstract}

Keywords: Sarcopoterium spinosum (L.); medicinal plants; cytotoxicity; inhibition; stachydrine; benzalkonium chloride; rutin; cancer cells 


\section{Introduction}

Cancer is the second leading cause of death [1], accounting for nearly 10 million deaths in 2020 worldwide [2], despite advances in chemotherapy development and tumor biology research. Surgery, radiotherapy, and chemotherapy are still the main forms of treatment. New discoveries in signalling pathways involved in tumor development, proliferation, and metastasis and also the completion of the Human Genome Project partially ameliorated some therapeutic problems. Nevertheless, the fundamental problems remain associated with the heterogeneity of the tumor, drug resistance, and systemic toxicities, since it often contains a diverse mixture of cells, and only a part of them can bounce back after treatment. The multiple, interconnected pathways presented in these cells complicate the efforts for providing effective therapies [3]. Troubleshooting remains based on the development of such small molecules which inhibit selectively and the most complexly undesired biological processes in a tumor cell, being able to selectively kill only tumor cells but not their healthy counterparts [4].

The cytotoxic-active compounds isolated from non-edible plant parts can also be used as health benefit agents, such plants as Sarcopoterium spinosum (L). This plant (syn: Poterium spinosum L.) is a spiny rosaceous dwarf shrub, and it is thought to have originated from the semi-arid transition zone between the Mediterranean and Irano-Turanian steppe vegetation zone, and then expanded westward [5]. Chemical constituents of S. spinosum and their bioactivity have been described in several works. Five pentacyclic triterpenoids [6], such as tormentic and urosolic acid, further beta-sitosterol [7], catechins, epicatechins [8], and proanthocyanidins [9] and other substances were identified in the root and aerial part of the extract. Most of the bioactive components are located in the thorns and leaves. Aldal'in [10] reported a gas chromatography-mass spectrometry (GC-MS) chromatogram of thorns and leaves methanolic extract of S. spinosum and showed seven major peaks for thorns and six major peaks for leaves, while three of major constituents (thymol, boric acid and dodecenedioic acid) were found in the extract of both the parts. The compounds of $\beta$-Dglucopyranoside, linoleic acid and cinnamic acid were found as major compounds only in thorns extract. Otherwise, benzoic acid, palmitic acid and malonic acid were found only in leaf extracts as major phytoconstituents. Henkin et al. [11] reported that tormentic acid from S. spinosum is suggested to be the major constituent extract, and to mediate its antiproliferative activity on several cancer cell lines. Tormentic acid plays an important role in the cytotoxicity exhibited by the extract [12]. S. spinosum extracts have been used in medical practice for the treatment of several disorders. Among other applications, the therapeutic applications in ethnopharmacological surveys are mostly for diabetes $[13,14]$ and disorders of the digestive system [15], pain relief [16], poisoning [17], anti-inflammatory effects [18], for the prevention and treatment of hepatic steatosis [19], and cancer [12]. Moreover, the anti-cancer effect of $S$. spinosum extract has also been reported. Durodola showed significant tumor inhibitory activity of a crude extract of S. spinosum in experimental animals [20].

The purpose of the present study was to investigate aerial parts of S. spinosum, perform an in vitro cell proliferation assay testing all extracted fractions and subfractions, perform the identification and subsequent synthesis of the molecule as a possible way to obtain the basic material for the synthesis of new anti-cancer compounds, and study three identified compounds in the most cytotoxic subfraction individually and in combination.

\section{Materials and Methods}

\subsection{Plant Material}

The aerial parts of S. spinosum were collected from the basis of Mount Tavor (ShibliUmm al-Ghanam, Israel $)\left(32^{\circ} 41^{\prime} 37.375^{\prime \prime} \mathrm{N}\right.$ and $\left.35^{\circ} 24^{\prime} 41.5645^{\prime \prime} \mathrm{E}\right)$ during fruiting periods in June 2012, and taxonomically identified by Professor Dr. T. Baranec, Slovak University of Agriculture in Nitra, Slovakia. A voucher specimen (DB-09-07-2012) of the plant is deposited at the Department of Botany, Slovak Agricultural University in Nitra. The plants were dried at room temperature, powdered, and homogenised in a grinder IKA A10 basic (IKA, Staufen, Germany). 


\subsection{Extraction and Isolation of Bioactive Compounds}

The bioactive compounds were extracted and fractionated according to their polarity as shown in Figure 1. Briefly, the powdered aerial parts including leaves and thorns of S. spinosum $(1.6 \mathrm{~kg})$ were sonicated with petroleum ether $\left(40-65^{\circ} \mathrm{C}\right)(3 \times 1.5 \mathrm{~L}, 1 \mathrm{~h}$ each). The resulting supernatants were collected and filtered through absorbent cotton, followed by evaporation of the solvent at $35{ }^{\circ} \mathrm{C}$ under low pressure. The resulting liquid residue was labelled as the PF (petroleum ether fraction, $15 \mathrm{~g}$ ). The defatted material remaining from petroleum ether extraction was re-extracted with $70 \%$ ethanol $(3 \times 2 \mathrm{~L}, 3 \mathrm{~h}$ under reflux each). This $70 \%$ ethanol extract was then filtered through absorbent gauze, and the filtrate was concentrated under low pressure to remove ethanol.

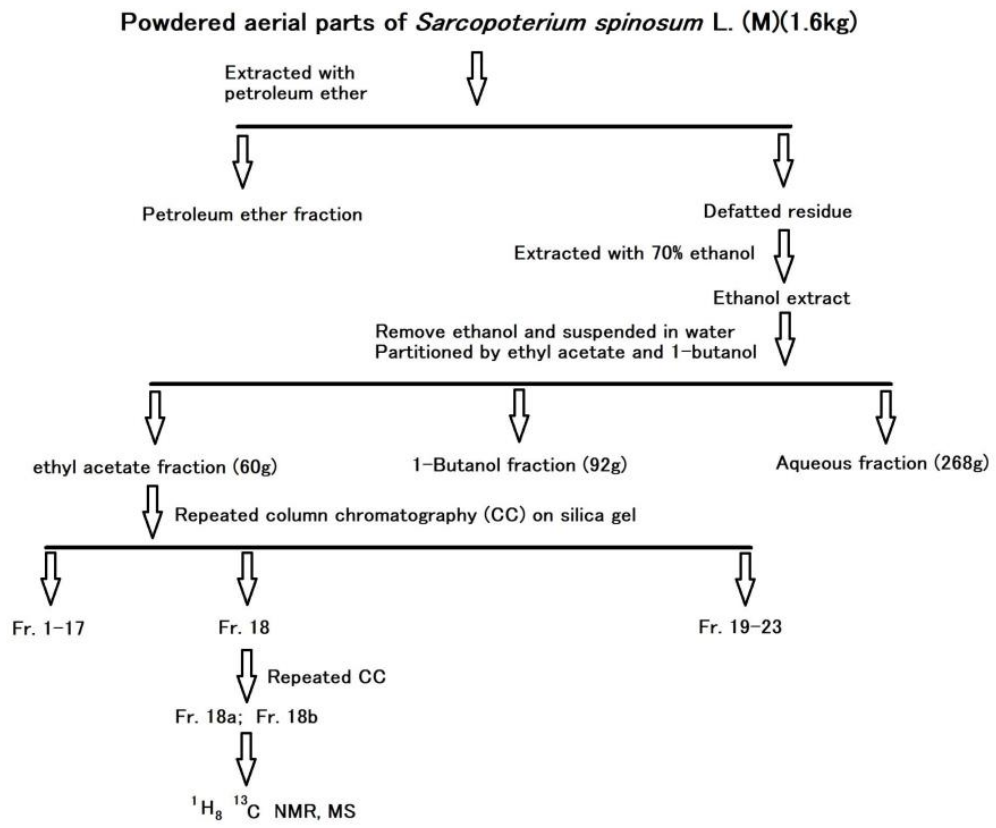

Figure 1. Extraction, fractionation, and column chromatography separation of the aerial parts extracts of S. spinosum (L.).

The resulting suspension was successively partitioned in 3 sequentially partitions with ethyl acetate and 1-butanol and the respective extracts combined. The ethyl acetate and 1-butanol extracts were evaporated to dryness under low pressure, while the aqueous layer was lyophilized. These 3 fractions were designated as AF (ethyl acetate fraction) (60 g), BF (butanol fraction) (92 g) and WF (water fraction) (268 g), respectively.

Since the highest cytotoxic activity was found in the AF, this fraction was subjected to column chromatography (CC), repeated many times due to the larger amount of extract, using silica gel $(75-150 \mu \mathrm{m}, 2 \times 50 \mathrm{~cm}$, flow rate $0.7 \mathrm{~mL} / \mathrm{min})$, the dose of solid AF was $0.5-0.7 \mathrm{~g} /$ column, firstly eluted with increasing polarities of a mixture of petroleum ether and ethyl acetate resulting in 13 fractions, and subsequently with increasing polarities of a mixture of ethyl acetate and methanol resulting in eight fractions (Fr.14-Fr.21) and followed with a mixture of acetone and water (1:1), resulting in two fractions (Fr.2-Fr.23). The most cytostatic-active fraction, the Fr.18 (ethyl acetate/methanol (5:5), $45 \mathrm{~mL} / 0.2 \mathrm{~g}$ of sample/separation cycle) was evaporated to dryness under low pressure. Then, the Fr.18 was separated by silica gel CCa (the same parameters as above) and eluted with a mixture of chloroform/methanol (10:1), with two fractions being collected to be studied further (Fr.18a that was designated as M8R and Fr.18b designated as M8N).

\subsection{Tumor Cell Lines}

Jurkat (acute T-lymphoblastic leukemia), HeLa (cervical adenocarcinoma), cells were maintained in RPMI 1640 medium supplemented with Glutamax-I. Caco-2 (human colorec- 
tal adenocarcinoma), MCF-7 (mammary gland adenocarcinoma), MDA-MB-231 (mammary gland adenocarcinoma), were maintained in Dulbecco's modified Eagle's medium (DMEM) with Glutamax-I and glucose. Both media were supplemented with $10 \%(v / v)$ fetal calf serum, penicillin $(100 \mathrm{IU} / \mathrm{mL})$ and streptomycin $(100 \mu \mathrm{g} / \mathrm{mL})$ (Invitrogen, Carlsbad, Kalifornia, UK), in humidified air with $5 \% \mathrm{CO}_{2}$ at $37^{\circ} \mathrm{C}$. Before each assay, cell viability was determined by the trypan blue (Invitrogen, UK) exclusion method and found to be greater than $95 \%$. 3T3 (murine fibroblasts) cell line was maintained in a growth medium consisting of high-glucose DMEM with sodium pyruvate (GE Healthcare, Piscataway, NJ, USA). The growth medium was supplemented with a $10 \%$ fetal bovine serum (FBS), penicillin $(100 \mathrm{IU} / \mathrm{mL})$ and streptomycin $(100 \mu \mathrm{g} / \mathrm{mL})$ (Invitrogen, Carlsbad, CA, USA) in an atmosphere containing $5 \% \mathrm{CO}_{2}$ in humidified air at $37^{\circ} \mathrm{C}$. Cell viability, estimated by trypan exclusion, was greater than $95 \%$ before each experiment.

\subsection{Cell Proliferation Assay}

Studied compounds were dissolved in DMSO. The final concentration of DMSO in the culture medium was $0.02 \%$ and exhibited no cytotoxicity. The effect of each fraction or individual compounds on cell proliferation was determined using a colorimetric microculture assay with the MTT (3-(dimethylthiazol-2-yl)-2,5-diphenyltetrazolium bromide) endpoint [21]. Briefly, $5 \times 10^{3}$ cells were plated per well in 96-well polystyrene microplates (Sarstedt AG \& Co., Nümbrecht, Germany). Twenty-four hours after seeding, different doses $(0.0019$ to $1.00 \mathrm{mg} / \mathrm{mL})$ of the tested chemicals were added. After $72 \mathrm{~h}$ of incubation, $10 \mu \mathrm{L}$ of MTT ( $5 \mathrm{mg} / \mathrm{mL}$; Sigma Aldrich Chemie, Steinheim, Germany) were added to each well. After an additional $4 \mathrm{~h}$ period, during which insoluble formazan was produced, $100 \mu \mathrm{L}$ of $10 \%$ sodium dodecylsulphate were added to each well and another $12 \mathrm{~h}$ of incubation enabled the formazan to dissolve. The absorbance was measured at $540 \mathrm{~nm}$ using the automated $\mu$ Quant ${ }^{\mathrm{TM}}$ Universal Microplate Spectrophotometer (Biotek, Oxfordshire, UK). The calculation formula is: cell proliferation rate $=($ experimental group A540 nm-zero adjustment group A540 nm)/(Control group A540 nm-zero adjustment group A540 nm) $\times 100 \%$. Absorbance of control wells was taken as $100 \%$, and the results were expressed as percentage of control.

\subsection{Synthesis of Stachydrine Hydroiodide}

Synthesis was carried out following the procedure described by [22] with modifications in the purification process. Briefly, L-proline $(1 \mathrm{~g} ; 8.69 \mathrm{mM})$ was dissolved in a solution consisting of sodium hydroxide $(1.03 \mathrm{~g} ; 25.75 \mathrm{mM})$ and dry methanol $(10 \mathrm{~mL})$. Methyl iodide $(1.60 \mathrm{~mL} ; 25.59 \mathrm{mM})$ was added at room temperature and the mixture was stirred for $6 \mathrm{~h}$ under gentle reflux. After cooling to room temperature, more methyl iodide $(0.54 \mathrm{~mL} ; 8.64 \mathrm{mM})$ was added and the mixture was again stirred for $6 \mathrm{~h}$ under gentle reflux. The reaction mixture was concentrated to dryness using a rotary evaporator (RVO 400, INGOS, Czech Republic). The light-yellow solid residue was dissolved in methanol $(15 \mathrm{~mL})$ and after addition of ethyl ether a white solid was precipitated, filtered and then washed with ethyl ether $(2 \times 5 \mathrm{~mL})$. The dry crude product was suspended in acetone $(50 \mathrm{~mL})$, boiled (5-10 $\mathrm{min}$ ) and filtered while hot. The filter cake was washed with acetone $(2 \times 15 \mathrm{~mL})$ and allowed to dry in the air. The yield obtained was $1.92 \mathrm{~g}$ (i.e., $82 \%)$ of the white crystals with a sharp melting point $\left(224^{\circ} \mathrm{C}\right)$.

\subsection{Nuclear Magnetic Resonance (NMR) Analysis}

${ }^{1} \mathrm{H}$ and ${ }^{13} \mathrm{C}$ spectra of sub-fraction M8R were obtained using a Varian VNMRS 600 instrument at the Faculty of Chemical and Food Technology STU in Bratislava. According to the detected nucleus, "Triple-resonance HNC" probe $\left({ }^{1} \mathrm{H}\right.$ and "indirect detected" heteronuclear experiments) or "Double resonance DBG" probe $\left({ }^{13} \mathrm{C}\right.$ detected experiments) was used. Besides ${ }^{1} \mathrm{H}$ and ${ }^{13} \mathrm{C}$ NMR experiments, additional experiments: gCOSY, gDQF-COSY, 2D TOCSY, HSQC and HMBC were performed if required (copies of the original spectra can be obtained from the corresponding author). All NMR experiments were performed by pulse 
programs provided by the spectrometer manufacturer. The standard operating parameters were used, and all NMR measurements were performed at $25^{\circ} \mathrm{C}$. Samples dissolved in different deuterated solvents (deuterated methanol $\left(\right.$ Met- $\left.\mathrm{d}_{4}\right)$, deuterated chloroform $\left(\mathrm{CDCl}_{3}\right)$, deuterated dimethyl sulfoxide (DMSO- $\left.\mathrm{d}_{6}\right)$, and deuterated water $\left(\mathrm{D}_{2} \mathrm{O}\right)$ ) were studied. NMR spectra of the major compound of sub-fraction M8R, proline betaine, synthesized as iodide at the Faculty of Science, Palacky University in Olomouc were obtained using a JEOL $400 \mathrm{MHz}$ instrument (JEOL, Tokyo, Japan). Measurements were undertaken at room temperature in a $\mathrm{D}_{2} \mathrm{O}$ solution. Unambiguous signals assignments were achieved with the help of $2 \mathrm{D}$ heteronuclear $\left({ }^{1} \mathrm{H}-,{ }^{13} \mathrm{C}-\right)$ and $\left({ }^{1} \mathrm{H}-,{ }^{15} \mathrm{~N}-\right) \mathrm{HMBC}$ experiments.

\subsection{Ultra High-Performance Liquid Chromatography-Mass Spectrometry (UPLC-MS) Analysis}

Analysis of stachydrine hydroiodide was also performed using a Waters Acquity UPLC-PDA-QDA system (Waters Corporation, Milford, MA, USA). The system used electrospray ion source (ESI) in positive and negative modes. Analyses were performed for the following conditions: security cartrig C18-4 $\times 3 \mathrm{~mm}$ (Phenomenex) and X Select HSS T3 column $\left(2.5 \mu \mathrm{m}, 3 \times 50 \mathrm{~mm}, 30^{\circ} \mathrm{C}\right)$. Mobile phase: linear gradient from 20 to $80 \%$ of acetonitrile in $0.01 \mathrm{M}$ ammonium acetate, and a flow rate $600 \mu \mathrm{L} / \mathrm{min}$ was used. MS parameters: TESI $600{ }^{\circ} \mathrm{C}$, Tcap $450{ }^{\circ} \mathrm{C},( \pm)$ ESI $\pm 3.0 \mathrm{kV}$. For the analysis was used solution of stachydrine hydroiodide $0.5 \mathrm{mg}$ in $1 \mathrm{~mL}$ of the solvent $(20 \%$ acetonitrile and $80 \%$ water). Time of the analysis $5.5 \mathrm{~min}$. Major component: UPLC-(+ESI)-MS: $\mathrm{m} / \mathrm{z} 144\left(\mathrm{M}+\mathrm{H}^{+}\right)$; $166\left(\mathrm{M}+\mathrm{Na}^{+}\right) ; 287\left(2 \mathrm{M}+\mathrm{H}^{+}\right) ; 309\left(2 \mathrm{M}+\mathrm{Na}^{+}\right)$; UPLC-(-ESI)-MS: $\mathrm{m} / \mathrm{z}$ 126.8; 140.8; 276.7. The positive mode was used for the confirmation of stachydrine, and the negative mode was used for the confirmation of the presence of hydrogen iodide.

\subsection{Chemical Materials}

MTT (purity > 97.5\%), alkyl-benzyl-dimethyl-ammonium chloride (benzalkonium chloride) (purity $>95 \%$ ), and Paclitaxel (purity $>97 \%$ ) were purchased from Sigma-Aldrich (Steinheim, Germany); and rutin sulphate sodium salt from Merck (Darmstadt, Germany). L-proline (purity > 99\%) and methyliodide (purity > 99\%), purchased from Sigma-Aldrich, St. Louis, MO, USA, were used to prepare L-proline betaine iodide (stachydrine hydroiodide or N, N-dimethyl-L-proline hydroiodide). All other solvents, petroleum ether $40-65^{\circ} \mathrm{C}$, ethyl acetate, ethanol, methanol, acetone and 1-butanol (Chemical Laboratories, Adamík, Slovakia) were of analytical reagent grade and used without any further purification.

\subsection{Statistical Analysis}

All experiments were performed in triplicate and the values of cell growth inhibition are expressed as mean \pm standard deviation (SD). The $\mathrm{IC}_{50}$ values were calculated using Graphpad Prism 5.04 (San Diego, CA, USA) software. Differences among means were tested for statistical significance $(p<0.01)$ using one-way analysis of variance (ANOVA).

\section{Results}

\subsection{Isolation of Cytostatic Compounds and Cell Proliferation Analysis}

The aerial parts of the plant material including leaves and thorns of $S$. spinosum were air-dried, ground to a powder and firstly extracted with petroleum ether. The defatted leftover was then re-extracted with $70 \%$ aqueous ethanol. The ethanol extract was further fractionated by being partitioned with ethyl acetate and 1-butanol, and all the obtained fractions PF (petroleum ether fraction), AF (ethyl acetate fraction), BF (1-butanol fraction), and WF (water fraction) were evaluated for their cytotoxic activity by MTT and spectrophotometric assays.

The average $\mathrm{IC}_{50}$ values for MCF-7 were found to be $22.0 \pm 6.5$, while for both HeLa and Caco-2 cell lines the $\mathrm{IC}_{50}$ was above $1000 \mu \mathrm{g} / \mathrm{mL}$ (Table 1). 
Table 1. IC50 value $(\mu \mathrm{g} / \mathrm{mL})$ of the ethyl acetate fraction $(\mathrm{AF})$ of S. spinosum L. extract and the more active fractions obtained from the column chromatography separation in various cancer and non-cancer cell lines.

\begin{tabular}{|c|c|c|c|c|c|}
\hline \multirow{2}{*}{ Sample } & \multicolumn{5}{|c|}{$\mathrm{IC}_{50}$ Value $^{\mathrm{a}}(\mu \mathrm{g} / \mathrm{mL})$} \\
\hline & $\mathrm{HeLa}^{\mathrm{b}}$ & ${\mathrm{MCF}-7^{\mathrm{c}}}^{\mathrm{c}}$ & Caco-2 $^{d}$ & MDA $^{\mathrm{e}}$ & $3 T 3^{f}$ \\
\hline M-AF & $>100$ & $22.0 \pm 2.7$ & $>100$ & $\mathrm{Nt}$ & nt \\
\hline M8 & $20.7 \pm 2.5^{*}$ & $5.9 \pm 1.1^{*}$ & $56.0 \pm 4.2$ * & $\mathrm{Nt}$ & nt \\
\hline M10 & $>100$ & $21.2 \pm 2.4$ & $>100$ & $\mathrm{Nt}$ & nt \\
\hline M8R & $5.8 \pm 1.1 *$ & $2.2 \pm 0.8^{*}$ & $9.5 \pm 1.4$ * & $62.5 \pm 3.8$ & 270.0 \\
\hline $\mathrm{M} 8 \mathrm{~N}$ & $>100$ & $>100$ & $>100$ & $>100$ & $>500$ \\
\hline
\end{tabular}

${ }^{\mathrm{a}}$ Data are the mean $\pm \mathrm{SD}(\mathrm{n}=3) .{ }^{\mathrm{b}}$ Cervical carcinoma cells. ${ }^{\mathrm{c}}$ Breast cancer cells. ${ }^{\mathrm{d}}$ Human colorectal adenocarcinoma. ${ }^{\mathrm{e}}$ Mammary gland adenocarcinoma. ${ }^{\mathrm{f}}$ Mouse fibroblast cells. ${ }^{*}$ Data with statistical significance against control (crude extract, M-AF): $p<0.01$. nt-not tested. Fr. 18 was designed as M8; Fr. 20 was designed as M10.

In the present study, further experiments were carried out on the AF extract in order to separate its cytotoxic components, being a column chromatography performed, resulting in the isolation of $23 \mathrm{sub}$-fractions that were studied concerning its effects on cell proliferation. Two fractions (Fr.18 and Fr.20) showed higher potential of cytotoxic activity than the others, Fr. 18 in all tested cells. The most cytotoxic-active fraction (Fr.18, respectively M8) showed the average $\mathrm{IC}_{50}$ values against HeLa, MCF-7, and Caco-2 cell lines as followed: $20.7 \pm 2.5,5.9 \pm 1.1$ and $56.0 \pm 4.2 \mu \mathrm{g} / \mathrm{mL}$, respectively. This fraction was subsequently purified and the first sub-fraction, designated as M8R, showed $\mathrm{IC}_{50}$ values against HeLa, MCF-7, Caco-2, and MDA cell lines as followed: $5.8 \pm 1.1,2.2 \pm 0.8,9.5 \pm 1.4$, and $62.5 \pm 3.8 \mu \mathrm{g} / \mathrm{mL}$, respectively (Table 1 ).

\subsection{Compounds Present in the Isolated Fraction}

Compounds present in the M8R sub-fraction were identified by spectroscopic analyses. From series of NMR spectra (standard ${ }^{1} \mathrm{H}$ and ${ }^{13} \mathrm{C}$, 2-dimensional COSY, HSQC and HMBC) it was possible to obtain a general idea of M8R composition. The major components found in M8R were stachydrine, benzalkonium chloride, and rutin (Figure 2).

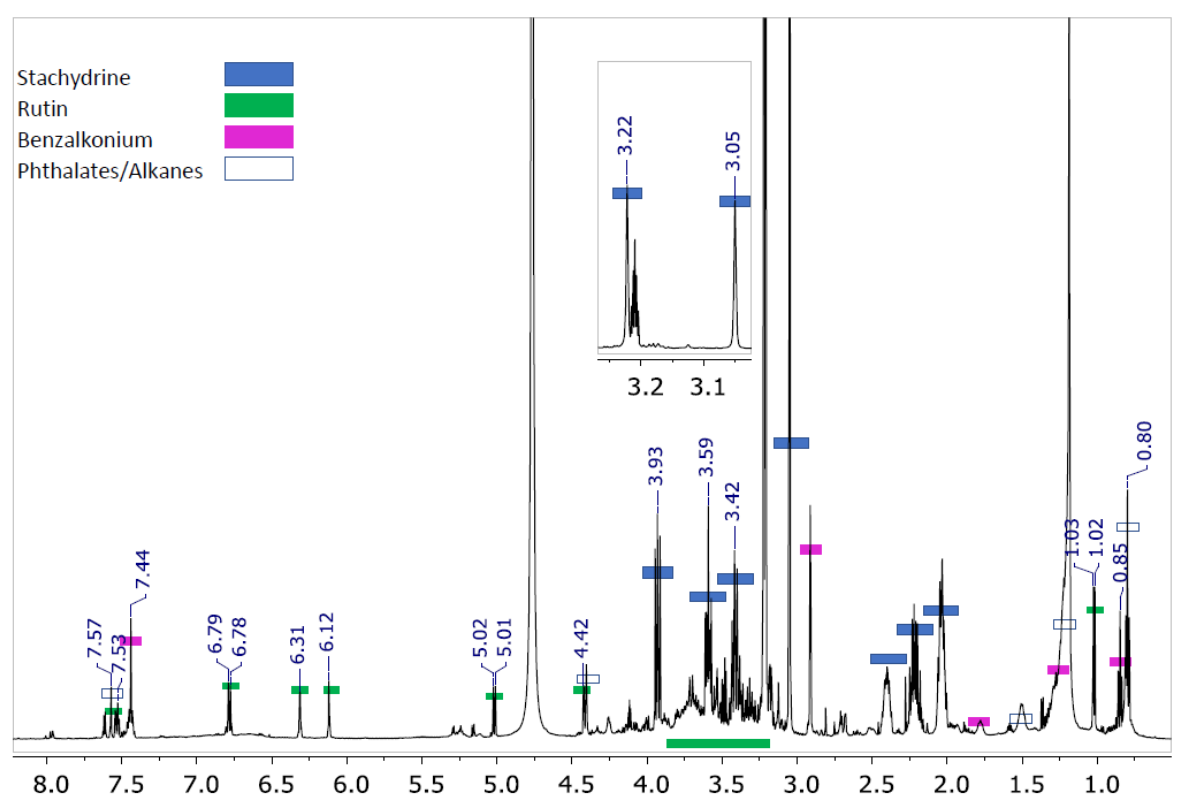

Figure 2. ${ }^{1} \mathrm{H}$ NMR (nuclear magnetic resonance) spectra of the most cytotoxic sub-fraction (M8R) in $\mathrm{CD}_{3} \mathrm{OD}$, isolated from S. spinosum after fractionation and purification. Alkane chain is correlated with aliphatic chain of benzalkonium chain. Phtalate signals-indicate the presence of phtalates in the plastic material used to transfer of the sample for analysis and mainly the use of silicone lubricants on glass cuts. 
These results were corroborated by NMR spectroscopic date (Table 2) and their structure, including the numbering of atoms, is shown in Figure 3.

Table 2. NMR spectroscopic data ${ }^{\text {a }}$ for the compounds present in M8R sub-fraction isolated from S. spinosum.

\begin{tabular}{|c|c|c|c|c|c|c|c|c|c|c|c|}
\hline \multirow[b]{2}{*}{$\mathbf{L}^{\mathbf{b}}$} & \multicolumn{4}{|c|}{ Stachydrine } & \multicolumn{2}{|c|}{ n-Alkane } & \multicolumn{2}{|c|}{ Rutin } & \multirow[b]{2}{*}{$\mathbf{L}^{\mathbf{b}}$} & \multicolumn{2}{|c|}{ Rutin } \\
\hline & $\begin{array}{c}{ }^{13} \mathrm{C} \\
\mathrm{NMR}\end{array}$ & & $\begin{array}{c}{ }^{1} \mathbf{H} \\
\text { NMR }\end{array}$ & & $\begin{array}{c}{ }^{13} \mathrm{C} \\
\text { NMR }\end{array}$ & $\begin{array}{c}{ }^{1} \mathbf{H} \\
\text { NMR }\end{array}$ & $\begin{array}{c}{ }^{13} \mathrm{C} \\
\mathrm{NMR}\end{array}$ & $\begin{array}{c}{ }^{1} \mathbf{H} \\
\text { NMR }\end{array}$ & & $\begin{array}{c}{ }^{13} \mathrm{C} \\
\text { NMR }\end{array}$ & $\begin{array}{c}{ }^{1} \mathbf{H} \\
\text { NMR }\end{array}$ \\
\hline 1 & & & & & 13.1 & 0.90 & & & 1 & 101.0 & 5.10 \\
\hline 2 & 76.2 & & 4.01 & & 21.7 & 1.30 & 157.9 & nt & $2^{\prime \prime}$ & 74.3 & 3.46 \\
\hline 3 & 25.2 & 2.30 & & 2.49 & 30.9 & 1.26 & 134.1 & nt & $3^{\prime \prime}$ & 76.7 & 3.40 \\
\hline 4 & 18.4 & & 2.12 & & 28.4 & $1.25-1.28$ & 178.0 & nt & $4^{\prime \prime}$ & 70.0 & 3.25 \\
\hline 5 & 66.6 & 3.68 & & 3.49 & 28.8 & $1.25-1.29$ & 157.0 & $\mathrm{nt}$ & $5^{\prime \prime}$ & 75.8 & 3.31 \\
\hline 6 & 43.7 & & 3.13 & & 28.8 & $1.25-1.30$ & 93.4 & 6.40 & $6^{\prime \prime}$ & 67.1 & 3.37 \\
\hline 7 & 51.3 & & 3.30 & & 28.8 & $1.25-1.31$ & 164.6 & nt & $1^{\prime \prime \prime}$ & 103.3 & 4.51 \\
\hline 8 & 169.4 & & - & & & & 98.5 & 6.20 & $2^{\prime \prime \prime}$ & 70.7 & 3.62 \\
\hline 9 & & & & & & & 161.5 & nt & $3^{\prime \prime \prime}$ & 70.8 & 3.52 \\
\hline 10 & & & & & & & 104.2 & nt & $4^{\prime \prime \prime}$ & 72.5 & 3.26 \\
\hline $1^{\prime}$ & & & & & & & 121.7 & nt & $5^{\prime \prime \prime}$ & 68.3 & 3.43 \\
\hline $2^{\prime}$ & & & & & & & 116.2 & 7.66 & $6^{\prime \prime \prime}$ & 16.5 & 1.10 \\
\hline $3^{\prime}$ & & & & & & & 144.4 & nt & & & \\
\hline $4^{\prime}$ & & & & & & & 148.3 & nt & & & \\
\hline $5^{\prime}$ & & & & & & & 114.6 & 6.87 & & & \\
\hline $6^{\prime}$ & & & & & & & 122.1 & 7.16 & & & \\
\hline
\end{tabular}

${ }^{a}$ Chemical shift in $\delta$ scale (ppm). ${ }^{b}$ Location (structure in Figure 3). NMR spectra of M8R sub-fraction were obtained at $600 \mathrm{MHz}$ in deuterated methanol (Met-d4).<smiles>C[N+]1(C)CCC[C@H]1C(=O)[O-]</smiles>

Stachydrine

Measured in Met-d4

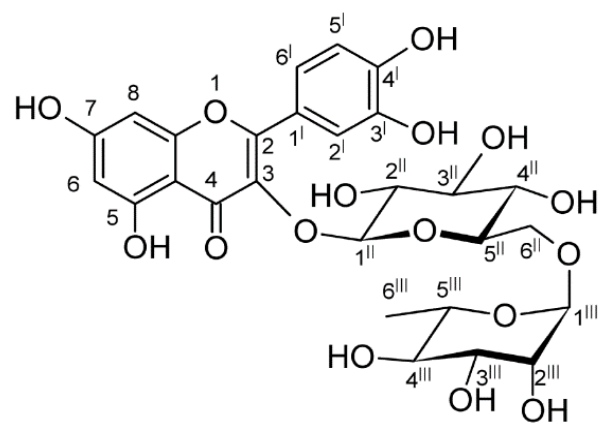

Rutin<smiles>CCOCSCPCC</smiles>

Measured in $\mathrm{CDCl}_{3}$<smiles>C[N+](C)(CCCCCCO)Cc1ccccc1</smiles>

Benzalkonium chloride

Measured in Met-d4

Figure 3. The chemical structure of the three major compounds presents in the M8R sub-fraction.

\subsection{Synthesis of Stachydrine and Its Identification}

The next working step was the preparation of stachydrine from L-proline and methyl iodide. After synthesis of stachydrine as hydroiodide, its structure was identified by several analyses. Some results of analyses are shown in Table S1 and in Figure S1 (Supplementary content), which enabled the identification of the nitrogen atom in stachydrine. After synthesis and identification of stachydrine, the two other compounds identified (benzalkonium chloride and rutin) were purchased. Quantification of the compounds in Fr. 18 was performed using the synthesized stachydrine and purchased standards of rutin and benzalkonium chloride, which simultaneously repeatedly confirmed their presence in fraction. The content of these compounds in the M8R sub-fraction were as following: stachydrine $-89 \%$, benzalkonium chloride $-7 \%$, and rutin $-4 \%$.

\subsection{Cytostatic Effect of the Substances Present in the Most Active Sub-Fraction}

There are several components of M8R sample that can be responsible for the observed cytostatic effect. Stachydrine, the compound present in a higher concentration, had alone a weak inhibitory effect (Table 3 ) on the growth of HeLa cells $\left(\mathrm{IC}_{50}=70 \mu \mathrm{M}\right)$. Benzalkonium 
chloride showed a strong growth suppressive effect against HeLa cells $\left(\mathrm{IC}_{50}=0.8 \mu \mathrm{M}\right)$ and MCF-7 cells $\left(\mathrm{IC}_{50}=5 \mu \mathrm{M}\right)$, but unfortunately also against normal cells (same intensity). The growth suppression of HeLa and MCF-7 cells by benzalkonium chloride at a concentration of $10 \mu \mathrm{M}$ was determined to be $88 \%$, and $65 \%$, respectively. The mixture of stachydrine with benzalkonium chloride at the same concentration of both compounds $(5 \mu \mathrm{M})$ completely suppressed the growth of all tested tumor cells (Jurkat, HeLa, MCF-7, and MDA cell lines). The same effect was observed for the mixture of $1 \mathrm{nM}$ stachydrine and $5 \mu \mathrm{M}$ benzalkonium chloride (1:1) (Table 3).

Table 3. Survival of cells (\%) at different concentrations of the compounds present in M8R subfraction isolated from S. spinosum.

\begin{tabular}{|c|c|c|c|c|c|c|}
\hline Compound & $\begin{array}{c}\text { Concentration } \\
(\mu \mathrm{M})\end{array}$ & Jurkat & HeLa & MCF-7 & MDA & $3 \mathrm{~T} 3$ \\
\hline \multirow[t]{6}{*}{ Stachydrine } & 100 & 100 & $28.1 \pm 2.2$ & $64.2 \pm 3.1$ & nt & $89.0 \pm 3.8$ \\
\hline & 10 & 100 & $81.2 \pm 3.0$ & $79.0 \pm 4.2$ & nt & 100 \\
\hline & 1 & 100 & $89.0 \pm 4.2$ & $80.4 \pm 4.3$ & nt & 100 \\
\hline & 0.1 & 100 & $91.2 \pm 5.1$ & $88.2 \pm 4.1$ & nt & 100 \\
\hline & 0.01 & 100 & $95.1 \pm 4.5$ & $86.3 \pm 4.3$ & nt & 100 \\
\hline & 0.001 & 100 & $95.0 \pm 5.0$ & 100 & nt & 100 \\
\hline \multirow[t]{6}{*}{ Benzalkonium chloride } & 100 & nt & nt & nt & nt & nt \\
\hline & 10 & nt & $12.1 \pm 2.0$ & $35.0 \pm 2.0$ & nt & $10.0 \pm 1.8$ \\
\hline & 1 & $69.1 \pm 3.2$ & $43.0 \pm 3.0$ & $64.2 \pm 3.1$ & nt & $42.2 \pm 2.9$ \\
\hline & 0.1 & $84.1 \pm 4.0$ & $81.1 \pm 4.0$ & $84.1 \pm 4.2$ & nt & $71.0 \pm 3.4$ \\
\hline & 0.01 & $92.2 \pm 5.1$ & $79.3 \pm 4.2$ & $92.3 \pm 5.0$ & nt & $81.1 \pm 3.9$ \\
\hline & 0.001 & $93.2 \pm 5.0$ & $79.1 \pm 4.3$ & $95.2 \pm 4.5$ & nt & 100 \\
\hline \multirow[t]{6}{*}{ Rutin } & 100 & $78.6 \pm 3.1$ & 100 & 100 & $94.0 \pm 4.2$ & $96.0 \pm 4.0$ \\
\hline & 10 & $85.9 \pm 3.7$ & 100 & 100 & $99.3 \pm 5.1$ & 100 \\
\hline & 1 & $91.3 \pm 4.2$ & 100 & 100 & $98.0 \pm 4.6$ & 100 \\
\hline & 0.1 & 100 & 100 & 100 & $98.6 \pm 4.4$ & 100 \\
\hline & 0.01 & 100 & 100 & 100 & $99.3 \pm 5.1$ & 100 \\
\hline & 0.001 & 100 & 100 & 100 & 100 & 100 \\
\hline $\begin{array}{l}\text { Mixture of stachydrine, } \\
\text { benzalkonium chloride and } \\
\text { rutin }(89 \%+7 \%+4 \%)\end{array}$ & & $0.28 \pm 0.07$ & $76.0 \pm 3.9$ & $35.5 \pm 1.6$ & $13.5 \pm 3.1$ & $52.0 \pm 3.3$ \\
\hline \multirow{6}{*}{$\begin{array}{c}\text { benzalkonium chloride }{ }^{\mathrm{a}} \\
\text { (in } \mu \mathrm{M} \text { of individual } \\
\text { compounds) }\end{array}$} & $5+5$ & nt & nt & nt & nt & $42.0 \pm 3.6$ \\
\hline & $2.5+5$ & nt & nt & nt & nt & $42.0 \pm 5.9$ \\
\hline & $1+5$ & nt & nt & nt & nt & $42.0 \pm 2.1$ \\
\hline & $0.1+5$ & nt & nt & nt & nt & $43.5 \pm 3.3$ \\
\hline & $0.01+5$ & nt & nt & nt & nt & $43.0 \pm 3.4$ \\
\hline & $0.001+5$ & nt & nt & nt & nt & $43.5 \pm 5.1$ \\
\hline \multirow[t]{3}{*}{ Paclitaxel } & 0.1 & ND & nt & $6.2 \pm 1.3$ & $12.1 \pm 1.9$ & nt \\
\hline & 0.01 & ND & $27.3 \pm 2.2$ & $31.0 \pm 2.6$ & $48.2 \pm 3.1$ & nt \\
\hline & 0.001 & ND & $68.0 \pm 3.2$ & $60.2 \pm 3.0$ & $72.4 \pm 3.3$ & nt \\
\hline DMSO & & 100 & 100 & 100 & 100 & 100 \\
\hline
\end{tabular}

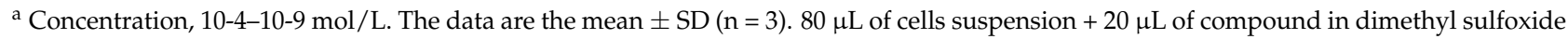
(DMSO) or in mixture of compounds: $10 \mu \mathrm{L}$ of the both compounds (1:1) in analyses were used. ND, not determined. Paclitaxel served as positive control. DMSO (a solvent of studied compounds) was used in a final concentration $0.02 \%$; nt - Not tested.

The $\mathrm{IC}_{50}$ values of Paclitaxel as positive control on HeLa, MCF-7, and MDA cells were as followed: $4.2 \mu \mathrm{M}, 3.8 \mu \mathrm{M}$, and $8.6 \mu \mathrm{M}$, respectively.

Rutin showed no inhibitory effect on cell growth of MCF-7 and HeLa at the concentrations of $10^{-4}$ to $10^{-9} \mathrm{M}$. Nevertheless, it showed a weak inhibitory effect against the growth of leukemic and mammary gland tumor cells.

\section{Discussion}

The present work shows the potential cytotoxic activity of S. spinosum extracts against the tested cell lines. The anti-proliferative properties of S. spinosum extracts were previously tested on several cancer cell lines (renal, prostate, melanoma), showing potential cytotoxic effect, which was partially attributed to the action of tormentic acid [20]. Among the four fractions studied in this work, AF was shown to be the one with the strongest anti- 
proliferative activity, but overall presenting a relatively weak cytotoxic activity, with better results being obtained against human breast adenocarcinoma and lung cell lines. The results point that, after purification, the different fractions show to be more active leading to better results, than those obtained before purification.

The isolated M8R sub-fraction contained three major compounds, two of which ammonium compounds, benzalkonium chloride and stachydrine, and also a flavonoid glycoside, rutin. While all three compounds have been reported in the literature, this is the first study to identify them in S. spinosum.

Stachydrine is a major constituent of different herbs, plants and fruits, and it is known to possess 0.6 medicinal effects. Rathee et al. [23] reported an in vitro anti-cancer activity of stachydrine against prostate tumor cell lines (PC3 and LNCaP). Nowadays, stachydrine is used as an osmo-protectant in clinics to promote blood circulation and to ameliorate HUVECs injury induced by anoxia-reoxygenation [24], and it is also able to suppress tubular epithelial cell apoptosis and to postpone renal intestinal fibrosis development in an animal model [25]. Stachydrine is also known to inhibit the angiotensin II-induced heart hypertrophy via blockade of the NF- $\kappa$ B signal pathway [26] and to improve high-glucose induced endothelial cell senescence [27] and it is used as a marker of citrus consumption [28]. In addition to its anti-cancer action, regulation of the uterus, neuroprotective effects, etc. the pharmacokinetic properties of stachydrine are also discussed [29].

Benzalkonium chloride is a quaternary ammonium compound used as a biocide, a cationic surfactant and a phase transfer agent to preserve cosmetics, mouthwashes, and skin cleansers [30] and can also be used for cold sterilization of medical and dental instruments [31]. The results of the present work are in accordance with the conclusions of Bouchemi et al. [32] and Ammar et al. [33]. The results reported by these authors showed that benzalkonium chloride, the most commonly used preservative in topical glaucoma medications, has widely and repeatedly shown toxic and pro-inflammatory effects at the level of the ocular surface and possibly in deeper structures like the trabecular meshwork. The mixture of stachydrine and benzalkonium chloride presented a significant synergistic effect to inhibit the growth of all tumor cells tested. On the other hand, antiproliferative activity of this mixture against non-cancer 3T3 cells was significantly weaker. The identification and observation of the synergism of cytotoxic effects of the mixture of stachydrine with benzalkonium chloride is, for the first time, mentioned in literature. The effect of benzalkonium chloride as the biocide is not surprising, but its synergistic effect with stachydrine could be used to extend the biological spectrum and enhance the efficacy of benzalkonium based disinfection products.

Rutin is a glycosylated flavonoid found in many plants and fruits [34] it is an antioxidant and can act as an inhibitor of angiogenesis with great potential for the control of some cancers. Although rutin already showed an inhibitory effect on the growth of ovarian and hepatic tumor cells [35], in the present experiments with other cell lines, rutin showed only a very weak inhibitory activity against the growth of MDA-MB-231 and Jurkat cells. Rutin also has other therapeutic properties, such as hypocholesterolemic, anti-asthmatic, and anti-inflammatory effects [36,37], and also inhibits platelet aggregation [38].

\section{Conclusions}

The present study demonstrated that an ethyl acetate fraction of S. spinosum and the three major compounds identified in it can exert a significant dose-dependent in vitro cytotoxicity especially against HeLa and MCF-7 cell lines, but also against normal cells. The mixture of stachydrine and benzalkonium chloride was shown to have a significant synergistic effect of cytotoxicity against all tested tumor cell lines. Rutin showed no inhibitory effect on the cell growth, nevertheless, it showed a weak inhibitory effect against the growth of leukemic and mammary gland tumor cells. These results provide a potent basis for further research and pharmacological activity of the isolated secondary metabolites from thorns and leaves extract will definitely give fruitful results. 
Supplementary Materials: MS spectroscopic analysis of stachydrine as hydroiodide (Table S1), its ${ }^{15}$ N HMBC spectra (Figure S1), identification and NMR signal assignment of benzalkonium anion, rutine and stachydrine-Are available in Supplementary content. The following are available online at https: / / www.mdpi.com/article/10.3390/app11115300/s1, Table S1, Figure S1, Benzalkonium anion, Rutine and Stachydrine-identification and NMR signal assignment.

Author Contributions: Conceptualization, J.H. and J.M.; Data curation, M.H. (Miroslav Haban); Formal analysis, T.L. and L.K.; Investigation, P.H. and L.K.; Methodology, J.H., J.M. and P.H.; Software, T.L.; Supervision, J.H. and J.M.; Validation, M.H. (Marta Habanova) and J.A.S.; Visualization, M.H. (Maria Holovicova); Writing-Original draft, M.H. (Marta Habanova), M.H. (Maria Holovcova) and D.Z.; Writing-Review and editing, J.H., J.M., P.H. and M.H. (Marta Habanova). All authors have read and agreed to the published version of the manuscript.

Funding: This research was funded by the Operational Programme Integrated Infrastructure for the project: Long-term strategic research of prevention, intervention and mechanisms of obesity and its comorbidities, IMTS: 313011V344, co-financed by the European Regional Development Fund. Furthermore, this publication is also the result of the project implementation MediPark, KošicePhase II., code ITMS2014+: 313011D103 supported by the Operational Programme Research and Innovation, funded by the ERDF. Thanks are due to the University of Aveiro and FCT/MCT for the financial support to LAQV-REQUIMTE (FCT UIDB/50006/2020) through national funds and, where applicable, co-financed by the FEDER, within the PT2020 Partnership Agreement.

Institutional Review Board Statement: Not applicable.

Informed Consent Statement: Not applicable.

Data Availability Statement: Not applicable.

Conflicts of Interest: The authors declare no conflict of interest.

\section{References}

1. Abotaleb, M.; Liskova, A.; Kubatka, P.; Büsselberg, D. Therapeutic Potential of Plant Phenolic Acids in the Treatment of Cancer. Biomolecules 2020, 10, 221. [CrossRef] [PubMed]

2. Ferlay, J.; Laversanne, M.; Ervik, M.; Lam, F.; Colombet, M.; Mery, L.; Piñeros, M.; Znaor, A.; Soerjomataram, I.; Bray, F. Global Cancer Observatory: Cancer Today. Lyon: International Agency for Research on Cancer. 2020. Available online: https:/ / gco.iarc.fr/today (accessed on 15 January 2021).

3. Ganesan, A.; Nolan, L.; Crabb, S.J.; Packham, G. Epigenetic therapy: Histone acetylation, DNA methylation and anti-cancer drug discovery. Curr. Cancer Drug Targets 2009, 9, 963-981. [CrossRef] [PubMed]

4. Eppert, K.; Takenaka, K.; Lechman, E.R.; Waldron, L.; Nilsson, B.; Van Galen, P.; Metzeler, K.H.; Poeppl, A.; Ling, V.; Beyene, J.; et al. Stem cell gene expression programs influence clinical outcome in human leukemia. Nat. Med. 2011, 17, 1086-1093. [CrossRef]

5. Litav, M.; Orshan, G. Biological flora of Israel 1. Sarcopoterium spinosum (L.) Spach. Isr. J. Bot. 1971, $20,48-64$.

6. Reher, G.; Buděšínský, M. Triterpenoids from plants of the sanguisorbeae. Phytochemistry 1992, 31, 3909-3914. [CrossRef]

7. Gupta, R.; Sharma, D.A.; Dobhal, M.; Sharma, M.; Gupta, R.S. Antidiabetic and antioxidant potential of $\beta$-sitosterol in Streptozotocin-induced experimental hyperglycemia. J. Diabetes 2011, 3, 29-37. [CrossRef]

8. Smirin, P.; Taler, D.; Abitbol, G.; Brutman-Barazani, T.; Kerem, Z.; Sampson, S.R.; Rosenzweig, T. Sarcopoterium spinosum extract as an antidiabetic agent: In vitro and in vivo study. J. Ethnopharmacol. 2010, 129, 10-17. [CrossRef]

9. Yaniv, Z.; Dudai, N. Medicinal and Aromatic Plants of the Middle-East, 1st ed.; Springer Sciences and Business Media: Dordrecht, The Netherlands, 2014; p. 314.

10. Aldal'In, H.K. Chemical composition of the methanolic extract from seeds, thorns and leaves of Sarcopoterium spinosum (L.) (Rosaceae) grown in Al-Tafila, Jordan. Res. Crop. 2018, 19, 315. [CrossRef]

11. Henkin, Z.; Rosenzweig, T.; Yaniv, Z. Sarcopoterium spinosum. In Medicinal and Aromatic Plants of the World; Springer Science and Business Media LLC: Berlin/Heidelberg, Germany, 2014; Volume 2, pp. 151-161.

12. Loizzo, M.R.; Bonesi, M.; Passalacqua, N.G.; Saab, A.; Menichini, F.; Tundis, R. Antiproliferative activities on renal, prostate and melanoma cancer cell lines of Sarcopoterium spinosum aerial parts and its major constituent tormentic acid. Anti-Cancer Agents Med. Chem. 2013, 13, 768-776. [CrossRef] [PubMed]

13. Rozenberg, K.; Rosenzweig, T. Sarcopoterium spinosum extract improved insulin sensitivity in mice models of glucose intolerance and diabetes. PLoS ONE 2018, 13, e0196736. [CrossRef]

14. Ben-Shachar, M.; Rozenberg, K.; Skalka, N.; Wollman, A.; Michlin, M.; Rosenzweig, T. Activation of Insulin Signaling in Adipocytes and Myotubes by Sarcopoterium Spinosum Extract. Nutrients 2019, 11, 1396. [CrossRef]

15. Al-Qura'N, S. Ethnopharmacological survey of wild medicinal plants in Showbak, Jordan. J. Ethnopharmacol. 2009, 123, 45-50. [CrossRef] 
16. Bachrach, Z.Y. Ethnobotanical studies of Sarcopoterium spinosum in Israel. Isr. J. Plant Sci. 2007, 55, 111-114. [CrossRef]

17. Friedman, J.; Yaniv, Z.; Dafni, A.; Palewitch, D. A preliminary classification of the healing potential of medicinal plants, based on a rational analysis of an ethnopharmacological field survey among Bedouins in the Negev Desert, Israel. J. Ethnopharmacol. 1986, 16, 275-287. [CrossRef]

18. Rozenberg, K.; Wollman, A.; Ben-Shachar, M.; Argaev-Frenkel, L.; Rosenzweig, T. Anti-inflammatory effects of Sarcopo-terium spinosum extract. J. Ethnopharmacol. 2020, 249, 112391. [CrossRef] [PubMed]

19. Wollman, A.; Daniel, T.; Rosenzweig, T. Sarcopoterium spinosum Inhibited the Development of Non-Alcoholic Steatosis and Steatohepatitis in Mice. Nutrients 2019, 11, 3044. [CrossRef] [PubMed]

20. Durodola, J. Tumour inhibitory effects of crude extracts from poterium spinosum. Planta Med. 1975, 27, 231-234. [CrossRef]

21. Mosmann, T. Rapid colorimetric assay for cellular growth and survival: Application to proliferation and cytotoxicity assays. $J$. Immunol. Methods 1983, 65, 55-63. [CrossRef]

22. Woster, P.M.; Murray, W.J. ChemInform Abstract: Synthesis and Biological Evaluation of Cyclic Analogues of 1-Carnitine as Potential Agents in the Treatment of Myocardial Ischemia. Chem. Inf. 1986, 17, 865-868. [CrossRef]

23. Rathee, P.; Rathee, D.; Rathee, D.; Rathee, S. In vitro anticancer activity of stachydrine isolated from Capparis decidua on prostate cancer cell lines. Nat. Prod. Res. 2012, 26, 1737-1740. [CrossRef]

24. Yin, J.; Zhang, Z.-W.; Yu, W.-J.; Liao, J.-Y.; Luo, X.-G.; Shen, Y.-J. Stachydrine, a Major Constituent of the Chinese Herb Leonurus Heterophyllus Sweet, Ameliorates Human Umbilical Vein Endothelial Cells Injury Induced by Anoxia-Reoxygenation. Am. J. Chin. Med. 2010, 38, 157-171. [CrossRef]

25. Zhang, C.; Lu, Y.; Zhou, Y.-J.; Tong, Q.-Q.; Qu, C.; Kang, T.-J. The Effect of Stachydrine on the Expression of Caspase-12 in Rats with Unilateral Ureteral Obstruction. J. Urol. 2014, 192, 1549-1554. [CrossRef]

26. Guo, W.; Zhang, C.; Liao, Y.-L.; Lv, R.; Wei, H.-C. Effect of Leonurus stachydrine on myocardial cell hypertrophy. Zhong Yao Cai Zhongyaocai J. Chin. Med. Mater. 2012, 35, 940-943.

27. Servillo, L.; D’Onofrio, N.; Longobardi, L.; Sirangelo, I.; Giovane, A.; Cautela, D.; Castaldo, D.; Giordano, A.; Balestrieri, M.L. Stachydrine ameliorates high-glucose induced endothelial cell senescence and SIRT1 downregulation. J. Cell. Biochem. 2013, 114, 2522-2530. [CrossRef]

28. Heinzmann, S.S.; Brown, I.J.; Chan, Q.; Bictash, M.; Dumas, E.M.; Kochhar, S.; Stamler, J.; Holmes, E.; Elliott, P.; Nicholson, J.K. Metabolic profiling strategy for discovery of nutritional biomarkers: Proline betaine as a marker of citrus consump-tion. Am. J. Clin. Nutr. 2010, 92, 436-443. [CrossRef]

29. Cheng, F.; Zhou, Y.; Wang, M.; Guo, C.; Cao, Z.; Zhang, R.; Peng, C. A review of pharmacological and pharmacokinetic properties of stachydrine. Pharmacol. Res. 2020, 155, 104755. [CrossRef] [PubMed]

30. Marple, B.; Roland, P.; Benninger, M. Safety Review of Benzalkonium Chloride Used as a Preservative in Intranasal Solutions: An Overview of Conflicting Data and Opinions. Otolaryngol. Neck Surg. 2004, 130, 131-141. [CrossRef] [PubMed]

31. Dart, R.; Caravati, E.M.; McGuigan, M.A. Medical Toxicology, 3rd ed.; Lippincott Williams \& Wilkons: Philadelphia, PA, USA, 2014; p. 1883.

32. Bouchemi, M.; Roubeix, C.; Kessal, K.; Riancho, L.; Raveu, A.-L.; Soualmia, H.; Baudouin, C.; Brignole-Baudouin, F. Effect of benzalkonium chloride on trabecular meshwork cells in a new in vitro 3D trabecular meshwork model for glaucoma. Toxicol. In Vitro 2017, 41, 21-29. [CrossRef] [PubMed]

33. Ammar, D.A.; Noecker, R.J.; Kahook, M.Y. Effects of benzalkonium chloride- and polyquad-preserved combination glau-coma medications on cultured human ocular surface cells. Adv. Ther. 2011, 28, 501-510. [CrossRef] [PubMed]

34. Harbaum, B.; Hubbermann, E.M.; Wolff, C.; Herges, R.; Zhu, Z.; Schwarz, K. Identification of Flavonoids and Hy-droxycinnamic Acids in Pak Choi Varieties (Brassica campestris L. ssp. chinensis var. communis) by HPLC-ESI-MS $\mathrm{n}$ and NMR and Their Quantification by HPLC-DAD. J. Agric. Food. Chem. 2007, 55, 8251-8260. [CrossRef] [PubMed]

35. Marcarini, J.C.; Tsuboy, M.S.F.; Luiz, R.C.; Ribeiro, L.R.; Hoffmann-Campo, C.B.; Mantovani, M.S. Investigation of cytotoxic, apoptosis-inducing, genotoxic and protective effects of the flavonoid rutin in HTC hepatic cells. Exp. Toxicol. Pathol. 2011, 63, 459-465. [CrossRef] [PubMed]

36. Raghav, S.; Gupta, B.; Agrawal, C.; Goswami, K.; Das, H.; Gupta, C. (Agrawal) Anti-inflammatory effect of Ruta graveolens L. in murine macrophage cells. J. Ethnopharmacol. 2006, 104, 234-239. [CrossRef] [PubMed]

37. Jung, C.H.; Lee, J.Y.; Cho, H.C.; Kim, J.C. Antiasthmatic action of quercetin and rutin in conscious guinea-pigs challenged with aerosolized ovalbumin. Arch. Pharmacal Res. 2007, 30, 1599-1607. [CrossRef] [PubMed]

38. Sheu, J.-R.; Hsiao, G.; Chou, P.-H.; Shen, A.M.-Y.; Chou, D.-S. Mechanisms Involved in the Antiplatelet Activity of Rutin, a Glycoside of the Flavonol Quercetin, in Human Platelets. J. Agric. Food Chem. 2004, 52, 4414-4418. [CrossRef] [PubMed] 